\title{
Weather and international price shocks on food prices in the developing world
}

\author{
Molly E. Brown ${ }^{\mathrm{a}, *}$, Varun Kshirsagar ${ }^{\mathrm{b}}$ \\ a Department of Geographical Sciences, University of Maryland, College Park, MD 20740, USA \\ ${ }^{\mathrm{b}}$ Independent Consultant, Washington, D.C. 20002, USA
}

\section{A R T I C L E I N F O}

\section{Article history:}

Received 18 February 2015

Received in revised form 2 August 2015

Accepted 11 August 2015

Available online $\mathrm{xxx}$

\section{Keywords:}

Climate change

Food security

Food prices

NDVI

\begin{abstract}
A B S T R A C T
In the context of a changing climate, there is an urgent need to better understand the impact that weather disturbances have on food affordability in the developing world. While the influence of international markets on local food markets has received considerable attention, in contrast, the potential influence of weather disturbances on local food markets has received much less attention. In fact, local weather disturbances may have an adverse impact on the poorest households in developing countries. Here we quantify the short-run impact of both weather disturbances as well as international price changes on monthly food prices across 554 local commodity markets in 51 countries during the period between 2008 and 2012. We find that almost 20\% of local market prices were affected by domestic weather disturbances in the short run, $9 \%$ by international price changes and $4 \%$ by both domestic weather disturbances and international price changes during the period. An improved understanding of the magnitude and relative importance of weather disturbances and international price changes on rural economies will inform public policies that are designed to mitigate the impact of adverse weather disturbances.
\end{abstract}

() 2015 Z. Published by Elsevier Ltd. This is an open access article under the CC BY license (http:// creativecommons.org/licenses/by/4.0/).

\section{Introduction}

In the context of a changing climate, there is an urgent need to better understand the impact that weather anomalies have on food security in the developing world. As Feng et al. (2013) document, increasing variability in seasonal rainfall is more pronounced in the tropics. Our analysis is not representative of the developing world but includes markets in Africa, South Asia, and Latin Americaregions that contain large segments of the world's poor. Tropical food insecure countries are also characterized by poor transport infrastructure and are among the least able to trade and offset weather risk (Brown 2014; World Bank 2014). The poor smallholder farmers in these regions are also more likely to engage in subsistence agriculture (Barrett, 2008b); (World Bank 2008) and are more likely to face the risks associated with climate-related domestic weather disruptions.

Despite the large literature that has examined local food prices in developing countries, there is limited systematic evidence on the relationship between domestic weather disturbances and local food prices (Baffes and Dennis 2013; Bradbear and Friel

\footnotetext{
* Corresponding author.

E-mail addresses: mbrown52@umd.edu (M.E. Brown), varun.kshirsagar@gmail.com (V. Kshirsagar).
}

2013; Garg et al., 2013; Hazell 2013; Headey and Fan 2008; Trostle et al., 2011; ul Haq et al., 2008; Von Braun 2008; Webb 2010). These studies involve household surveys that cover two or three time periods, or use simulated data instead of observations. Here we examine 60 months of price data for each of the 554 markets in order to quantify the impact of weather disturbances on food prices.

Lack of access to food due to affordability is a primary cause of food insecurity in urban areas, therefore it is important for policy makers to understand how domestic weather disturbances affect local prices (FAO, 2012). In the aftermath of the 2008 crisis, international organizations including the International Food Policy Research Institute (IFPRI), the World Bank Group, the UN's Food and Agricultural Organization, and the Group of 20 (G20) assumed that local prices in developing countries rose in response to large increases in international commodity prices (Swinnen and Squicciarini 2012). In competitive, efficient food markets, local weather shocks should have no influence on local prices (Samuelson 1965). We find that local weather disturbances do affect food prices because the assumptions of the underlying economic theory are unrealistic. If local production is affected by weather disturbances, do international commodity prices matter more to local market prices? Quantifying the influence of international commodity price changes simultaneously with 
domestic weather on local markets during this period is one of the goals of this paper.

In agricultural economics there is a large literature on market integration (Barrett 2008a; Cook 1999; Ihle et al., 2011; Zant, 2013). Taken together, this literature has not quantified the mechanisms that prevent food markets in developing countries from being better integrated. Further, we are not aware of a study that examines the influence of domestic weather disturbances across large set of countries and markets, although the influence of weather disturbances on local food markets is widely acknowledged. Consequently, and in contrast to studies that have examined food market integration across a large set of countries (e.g., Minot (2011), our study focuses on quantifying impacts of both weather disturbances and world food prices as drivers of local food prices. This will help clarify the mechanisms that drive local food price movements. Further analysis could attempt to bridge our approach with the food market-integration literature.

We categorize local food markets as being influenced by domestic weather disturbances, international commodity shocks, or both. We are aware that many other influences affect local food prices, including regional markets, distance to ports, informal trade, currency and exchange rates, degree of engagement in the international market and many other factors. We take a minimalist approach in order to enable analysis and response by international organizations such as Famine Early Warning Systems Network and the World Food Program who have a lot of local qualitative intelligence about the functioning of food markets, but need a way to analyze food affordability across multiple regions at the same time. Absent policy interventions, markets influenced by domestic weather disturbances are more vulnerable to increasing rainfall variability (Byerlee et al., 2006). To measure weather disturbances in a way that is comparable across agro-ecosystems and continents, we use a widely used satellite-derived vegetation index that integrates rainfall and temperature impacts on biomass and enables comparability across countries and ecosystems (Becker-Reshef et al., 2010; Pettorelli et al., 2005; Pfeifer et al., 2014). A similar approach is used by the Group on Earth Observation's Global Agriculture Monitoring Initiative (GeoGLAM) sponsored by the Group of Twenty (G20), whose objective is to monitor food production across all major agricultural production zones.

The international community responded to the 2007/8 international food price spike by channeling considerable resources into the agricultural sectors of developing countries (Swinnen and Squicciarini 2012). The rationale for these actions was predicated on the assumption that higher global food prices engendered a large poverty increase across the developing world (Swinnen and Squicciarini 2012). In fact, a growing literature provides evidence that international food price shocks exert a muted impact on food prices in developing countries (Headey 2013; Minot 2011) Here we show that, for our sample of 554 local food markets, there are many more markets in the developing world that are influenced in the short run by local weather disturbances $(23.2 \%)$ than those that are influenced by international food price shocks (12.4\%). Consequently, our results speak to the urgent need for greater policy emphasis on understanding and mitigating local weather disturbancesregardless of the frequency and occurrence of international food price spikes.

Since food staple food demand shifts are rarely large, significant increases in local prices typically indicate local or regional shortages. In lower income households that are food insecure, this results in lower than optimal food consumption and poor nutrition outcomes (Golden et al., 2011; Handa and Mlay, 2006). Therefore, food prices are often the most accurate and timely indicators of changes in both local food scarcity and food insecurity. Local staple food prices can be collected for representative markets on a regular basis and at a reasonable cost, providing insight on the food security of local communities (Garg et al., 2013). Information on food prices also allows systematic comparisons across time, agro-ecological food systems, and political boundaries.

\subsection{Model assumptions and structure}

Given our hypothesis that domestic weather and changes in the international price of commodities will affect local food prices, we develop a set of models is compared against a random walk benchmark. Samuelson (1965) was one of the first to demonstrate that under certain conditions (including rational expectations and behavior) price series would exhibit random walk behavior (Samuelson 1965). These ideas were further developed in seminal work by Fama (in particular, (Fama, 1965, 1970; Malkiel, 1973). At the same time, an influential literature developed a theory of commodity price dynamics that rested on harvest shocks and competitive storage with profit maximizing intermediaries (Gustafson 1958; Newbery and Stiglitz 1981; Wright and Williams 1991). An ambitious research program undertaken by Deaton and Laroque tested this theory using commodity price data (Deaton and Laroque 1992, 1996).

While Deaton and Laroque's program could explain commodity price spikes, they concluded that the autocorrelation of the price time series was not consistent with the competitive storage model. Further, none of their methods explicitly measured weather disturbances. Food price changes in developing countries exhibit pronounced seasonal behavior (Sahn, 1989). This is due to inadequate storage and transportation. It is also worth noting that, even for stock prices that are traded in the most sophisticated markets in the developed world, it has been shown that price dynamics may not be random (Lo and MacKinlay, 2011). Food markets in developing countries are characterized by a wide-range of inefficiencies (World Bank, 2008) and likely to be far less efficient than financial markets in developed countries.

In this context, here we test other specifications against a benchmark model that is a random walk (augmented to adjust for seasonality). Given the market inefficiencies mentioned above, it is possible that lagged weather and world price shocks will influence local food price dynamics. Therefore, we allow for three other possible data generating processes. First, that food prices may be influenced by domestic weather disturbances. Second, that food prices may be influenced by prices at which food commodities are traded on international markets. And finally, a data generating process in which food prices may be influenced by both international prices and weather disturbances. These three models are described below in Section 3.

\section{Data}

\subsection{Vegetation index data and pre-processing strategy}

We use the vegetation index measure derived from remote sensing observations as a proxy for yield changes. Vegetation index data have long been used to examine changes in agricultural production due to changes in plant biomass from abiotic stresses (Becker-Reshef et al., 2010; Fensholt 2004; Hoefsloot et al., 2012; Karnieli et al., 2010; Vrieling et al., 2011). A review of the NDVI-crop literature given by Funk and Budde (2009) focuses on the strong relationship between vegetation indices and crop yields in tropical countries such as the Sahel, where 93\% of the variation in yields could be detected in semi-arid ecosystems (Rasmussen 1992). Using vegetation index from NASA's moderate resolution imaging spectroradiometer (MODIS), Funk and Budde (2009) were able to estimate variations in crop production in Zimbabwe in a period 
when rainfall datasets were poorly calibrated due to lack of ground observations and crop models were reporting variations in production that were unrealistic due to a massive reduction in the baseline production from land redistribution in 2001. BeckerReshef et al. (2010) describe how vegetation remote sensing is making a contribution to global estimates of cropland distribution, crop development and yield estimation through the USDA Foreign Agriculture Service, and is the foundation for the GeoGLAM project sponsored by the Group of Twenty (G20).

Biophysical parameters observed with satellite remote sensing are direct measures of the light or electromagnetic radiation reflected from plants on the earth surface. Measures of vegetation health occur on spatial scales of sub-meter to tens of kilometers and in temporal resolution from hourly to monthly. Vegetation data provides information on the amount of photosynthetic activity of chlorophyll molecules that is linearly scalable from cell to leaf to plant to landscape. The normalized difference vegetation index (NDVI) is a ratio of the light reflected in the red portion (RED) of the electromagnetic spectrum versus the light reflected in the near-infrared (NIR) (Tucker 1979). The index is computed by as follows:

$\mathrm{NDVI}=\frac{\mathrm{NIR}-\mathrm{RED}}{\mathrm{NIR}+\mathrm{RED}}$

NDVI provides a measure of the greenness of the plants on a landscape and is often used as a proxy for the productivity of a cereal crop and therefore its yield (Pettorelli et al., 2005; Vrieling et al., 2011). Here we use vegetation data from the moderate resolution imaging spectroradiometer (MODIS) monthly data for each country from the $0.05^{\circ}$ resolution climate modeling grid (CMG) data from the NASA Moderate Resolution Imaging Radiometer (MODIS) instrument from 2002 (Justice et al., 1998). One can analyze many consecutive measurements of NDVI over weeks, months or years to gain an understanding of how vegetation is performing in a region over time. The data is available within one day after observation, and thus can be used in near real time in an operational system.

We calculate the monthly anomaly for any one $5 \mathrm{~km} \times 5 \mathrm{~km}$ location by subtracting the observation from the current month from the mean for the month from 2002 to 2012. Although these data are available at $250 \mathrm{~m}$ resolution, we selected the $5000 \mathrm{~m}$ or $0.5^{\circ}$ resolution to reduce processing time and to reduce error by averaging across regions. For this analysis, we consider only those anomalies greater than $10 \%$ or 0.1 NDVI units. To make the data usable within the modeling framework, we extracted without averaging the CMG data into a comma-delimited file with latitude, longitude, country code, and land cover type for all pixels within each countries' borders.

The measurements are aggregated across time to a monthly time scale and across space to four domestic clusters (using a $k$ means clustering algorithm). The models are run for each of the four clusters and the optimal model is reported. Further, pixels that satisfy the following criteria are used to calculate the average: (i) marked as being cropland or cropland-mix according to the MODIS land cover classification (Friedl et al., 2002) and (ii) the median maximum monthly change is greater than 0.5 NDVI units and the median minimum monthly change is less than -0.5 NDVI units (to further ensure that the pixels cover areas that are seasonal). Only months for which the median change is increasing by 0.2 are considered, with all other months are set to zero. This ensures that the weather disturbance signals are not confounded with a harvest and the signal is restricted to months that coincide with the growing season.

\subsection{Local food prices}

The monthly consumer food prices used in this paper paper are from a continuously up-dated price database comprised of food prices from 60 months from 2008 to 2012, with a maximum of three months missing during the time series. Data is from 215 markets in 51 countries, collected by the United Nations Food and Agriculture Organization (FAO) and the World Food Program (WFP) with 554 unique commodity-location pairs. Most of the data is available from the FAO at the Global Information and Early Warning Sys-tem (GIEWS) website: (http://www.fao.org/giews/ pricetool2/) and WFP (http://foodprices.vam.wfp.org/AnalysisMonthly-Price-DataADV.aspx). There are several data sources for each country's information. Monthly international prices of maize, wheat and rice are obtained from the World Bank. The international price of maize is used for the millet and sorghum price locations, since there is no commonly reported international price for these commodities.

\section{Methods}

In this paper, we incorporate monthly domestic weather disturbances and international commodity prices in a state space model using a Kalman Filter to estimate parameters of a price dynamic system (Shumway and Stoffer 2010). We apply two criteria to determine whether a particular model works better than another for a location-commodity pair: the corrected Akaike Information Criterion (AICc) is lower than the seasonal random walk as well as all other specifications, and the estimated coefficient has the expected sign with an attached p-value for a one-sided t-test that is below 0.05. The model uses weather disturbances estimated by satellite-derived normalized difference vegetation index over cropped regions of each country as well as shocks from international commodity prices, as measured at international ports, and their interactions. In this section, we first describe the models, then we present the state space Kalman filter approach, and then model selection and post-estimation analysis.

\subsection{Model description}

\subsubsection{Model I: a (generalized) seasonal random walk}

The first model is used as a benchmark against which the others are measured. Define $F_{t}$ to Net Food Demand at time $t$ and at to be the time varying slope at time $t . F_{t}$ is assumed to be directly proportional to food scarcity and price. The slope at is allowed to change over time and may be mean reverting $\left(\left|\alpha_{2}\right|<1\right)$ or a random walk $\left(\alpha_{2}=1\right)$. This formulation is intended to capture the idea that there are (latent) factors associated with changing expectations that influence local food price dynamics. In periods when prices may be rising quickly, a forward momentum may develop that puts pressure on prices, independent of fundamental factors. We do not assume this effect, but rather allow for the possibility. It is also possible that these mechanisms are absent-in which case, either $\alpha_{1}$ will simply be estimated to be zero or $\zeta_{t}$ will be zero and $\alpha_{2}$ will be one.

$F_{t}=F_{t-1}+\alpha_{1} a_{t}+\beta_{1} \sin \left(\frac{2 \pi t}{12}\right)+\beta_{2} \cos \left(\frac{2 \pi t}{12}\right)+\varepsilon_{t}$

$a_{t}=\alpha_{2} a_{t-1}+\zeta_{t}$

The error terms are assumed to be iid normal and independent of each other.

$\varepsilon_{t} \sim \operatorname{NID}\left(0, \sigma_{\varepsilon}^{2}\right), \zeta_{t} \sim \operatorname{NID}\left(0, \sigma_{\zeta}^{2}\right), \Sigma_{t} \sim \operatorname{NID}\left[\begin{array}{cc}\sigma_{\varepsilon}^{2} & 0 \\ 0 & \sigma_{\zeta}^{2}\end{array}\right]$ 
To simplify notation, this system can be expressed in matrix form in the following manner.

$S=\left[\begin{array}{c}F_{t} \\ \alpha_{t}\end{array}\right], A=\left[\begin{array}{ll}1 & \alpha_{1} \\ 0 & \alpha_{2}\end{array}\right], c=\left[\begin{array}{cc}\beta_{1} & \beta_{2} \\ 0 & 0\end{array}\right], C=\left[\begin{array}{c}\sin \left(\frac{2 \pi t}{12}\right) \\ \cos \left(\frac{2 \pi t}{12}\right)\end{array}\right]$

Note, the state vector at time $t, S_{t}$, consists of the net food demand term at time $t$ (which is related to price) as well as the momentum term $\left(a_{t}\right)$.

$S_{t}=A S_{t-1}+c C+\Sigma_{t}$

Let $p_{t}$ be the natural log of the observed food price at time $t$. We assume that $p_{t}$ is related to $\mathrm{Ft}$ with no observation error.

$p_{t}=Z_{t} S_{2}=\left[\begin{array}{ll}1 & 0\end{array}\right] S_{t}$

This system represents a generalized random walk. Assigning values for 4 parameters transforms the system to a random walk with a drift. Specifically, the evolution of $F_{t}$ collapses to a simple random walk with a drift if $\beta_{1}=0, \beta_{2}=0, \sigma \zeta_{2}=0$ and $\alpha_{2}=1$. Further, if $\alpha_{1}$ is also 0 , then the system collapses to a simple random walk. We use Eqs. (4)-(6) as the benchmark model. The next three probability models involve amendments to the coefficient matrix $(c)$ and the exogenous vector $(C)$ that allow for the influence of weather and/or international price shocks.

\subsubsection{Model II: weather disturbances influence local prices}

To allow for the influence of weather disturbances, we augment the coefficient matrix and exogenous vector in Eqs. (4)-(6) by incorporating a lagged normalized difference vegetation anomaly (NDVI) term. Consequently, the two matrices are now expressed in the following manner.

$c=\left[\begin{array}{ccc}\beta_{1} & \beta_{2} & \beta_{\mathrm{NDVI}} \\ 0 & 0 & 0\end{array}\right], C=\left[\begin{array}{c}\sin \left(\frac{2 \pi t}{12}\right) \\ \cos \left(\frac{2 \pi t}{12}\right) \\ \mathrm{NDVI}_{t-1}\end{array}\right]$

Note, the lagged NDVI anomaly acts as a shock to the price dynamical system and may amplify the (normal) seasonal effects. We would expect $\beta_{\mathrm{NDVI}}$ to be negative. This is because a positive NDVI anomaly is associated with a greater than normal rainfall event and a negative NDVI anomaly is associated with an adverse rainfall event. The magnitude of $\beta_{\mathrm{NDVI}}$ depends on the slope of the local food demand curve. In other words, $\beta_{\mathrm{NDVI}}$ is expected to be closer to zero when local food markets are better connected to the outside world. This is because local weather disturbances will have a smaller influence on local food prices. Conversely, when markets are isolated, local food supply is largely determined by local weather. It is well documented (World Bank, 2007) that the poorest regions are often tenuously connected with outside markets. As a consequence, for this type of market, a given weather disturbances will have a larger influence on local food prices. There have been, in the recent past, considerable investments financed by the international donor community to strengthen local food supply chains that may reduce the influence of local weather disturbances. However, as we show, there remains a strong relationship between local weather disturbances and local food price dynamics for a significant proportion of the markets that we study.

\subsubsection{Model III: international prices influence local prices}

Alternatively, to allow for the influence of international price shocks, we augment the coefficient matrix and exogenous vector in Eqs. (4)-(6) by incorporating a lagged price change term. Since, international prices are not seasonal, a change from the last period is interpreted to be a shock. Note, in contrast, the NDVI anomaly represents a difference from the median for a given month. Therefore, to capture the influence of international price shocks, the two matrices are now expressed in the following manner.

$c=\left[\begin{array}{ccc}\beta_{1} & \beta_{2} & \beta_{W \text { price }} \\ 0 & 0 & 0\end{array}\right], C=\left[\begin{array}{c}\sin \left(\frac{2 \pi t}{12}\right) \\ \cos \left(\frac{2 \pi \mathrm{t}}{12}\right) \\ w \text { price }_{t-1}\end{array}\right]$

In a similar manner to the NDVI anomaly (Eq. (7)), the possible influence of the lagged international price shock is assumed to be a shock to system. In contrast, $\beta$ wprice is expected to be positive. For local markets that are connected to world markets, we expect $\beta$ wprice to be significantly different from zero. Further, the magnitude of $\beta$ wprice is directly related to the degree to which the local market is influenced by world market prices.

\subsubsection{Model IV: world prices and weather disturbances influence local prices}

Finally, to allow for the influence of both international price shocks and anomalous weather, we augment the coefficient matrix and exogenous vector in Eqs. (4)-(6) by incorporating a lagged price change term as well as the lagged NDVI anomaly.

$c=\left[\begin{array}{cccc}\beta_{1} & \beta_{2} & \beta_{\text {NDVI }} & \beta_{\text {wprice }} \\ 0 & 0 & 0 & 0\end{array}\right], C=\left[\begin{array}{c}\sin \left(\frac{2 \pi t}{12}\right) \\ \cos \left(\frac{2 \pi t}{12}\right) \\ \mathrm{NDVI}_{t-1} \\ w \text { price }_{t-1}\end{array}\right]$

This dynamical system has just eight free parameters $\left(\alpha_{1}, \alpha_{2}, \sigma_{\mathrm{c} 2}\right.$, $\left.\sigma_{\zeta 2}, \beta_{1}, \beta_{2}, \beta_{\mathrm{NDVI}}, \beta_{w \text { price }}\right)$, yet it incorporates the time-varying latent momentum, seasonal influences, anomalous weather influences, as well world price influences. Given that the price time series we study has only 60 observations, this formulation provides a balance between parsimony and the flexibility required to capture fairly complex local food price dynamics.

In this section, we presented four probability models used to integrate remote sensing observations of domestic weather disturbances and international price changes into a set of plausible data generating processing for each price time series we study. In reality it is possible that a food prices switch between processes for a given market. However, given the short sample (60 observations) we assume that each price series is best modeled (and approximated) by only one of the processes. Section 3.2 below presents the statistical inference technique that has two steps. In the first step, we estimate (for all four probability models) parameters and a goodness of fit measure - the corrected Akaike Information Criterion (AICc) - under the assumption that the price time series is a realization of a given probability model. In the next step, we use the AICc measure, as well as the magnitudes, signs and significance of the estimated parameters to classify each price time series as belonging to one of the four models discussed in this section.

\subsection{The statistical estimation method}

State Space models that employ the Kalman filter have been widely used to estimate parameters of linear dynamical systems (Durbin and Koopman, 2012; Harvey, 1990; Shumway and Stoffer, 2010). In our context this estimation method is appealing for two reasons. First, food price dynamics are inherently non-stationary. As mentioned above, there are some periods when momentum, which is the influence of recent price increases after controlling for seasonality and other shocks, drives food prices. Error correction 
models and OLS are unable to capture this easily, while a Kalman filter is ideally suited to model this latent momentum in parsimonious manner. By controlling for this latent momentum, estimated by Eq. (2), we are better able to estimate the impact of market fundamentals. This is demonstrated by the simulations presented here, but also see Meinhold and Singpurwalla (1983) for an intuitive explanation. Second, we are able to directly test and reject the random walk hypothesis even after controlling for seasonality, which is a core assumption in economics (Samuelson 1965).

Assume that the state vector St has an initial state that has a normal distribution as follows:

$S_{1} \sim N\left(a_{1}, s_{1}\right)$

Let $v_{t}$ be the difference between the realized price and the predicted price.

$v_{t}=p_{t}-F_{t}$

Define $G_{t}$ to be the variance of $v_{t}$ conditional on information in period $t^{-1}$

$G=Z_{S_{t}} s Z^{\prime}+\Sigma_{t}$

$a_{(t \mid t)}=a_{t}+s_{t} Z^{\prime} G_{t}^{-1} v_{t}$

$s_{(t \mid t)}=s_{t}+s_{t} Z^{\prime} G_{t}^{-1} Z s_{t}$

Let information at time $t$ be given by $I_{t}$. Then the mean and variance of the state vector are updated in the following manner.

$a_{t+1}=\operatorname{AE}\left(S_{t} \mid I_{t}\right)$

$S_{t+1}=\operatorname{AV}\left(S_{t} \mid I_{t}\right) A^{\prime}+\Sigma_{t}$

These equations lead to the key prediction step.

$a_{t-1}=A a_{t}+K_{t} v_{t} K_{t}=A s_{t} Z G_{t}^{-1}$

Here, $K_{t}$ is the Kalman gain, which measures the extent to which new information changes the estimates of the state vector. It is increasing in the estimated variance of the state vector but decreasing in the estimated variance of the error covariance matrix $\left(\Sigma_{t}\right)$. The estimation is complete when the st matrix converges to a steady state. The system is estimated using maximum likelihood. See Durbin and Koopman (2012) for a complete treatment of the estimation methodology.

\subsection{Model selection and post-estimation analysis}

The corrected Akaike Information Criterion (AICc) is computed for all four models. The optimal model is one that minimizes the AICc described below. In these equations, $p$ is the number of parameters to be estimated, $n$ is the sample size, and $L$ is the $\log$ likelihood. Model I has 6 parameters, Models II and III have 7 parameters and Model IV has 8 parameters. All estimations use 59 observations. We use the AICc here as it is appropriate for time series with small samples and has strong theoretical properties (Brockwell and Davis 2009; Hurvich and Tsai 1989).

$\operatorname{AIC}_{c}=2 p-2 \ln (L)+\frac{(2 p)(p+1)}{n-p-1}$

In simulation results in the next section, we show that a selection method that uses the corrected AIC successfully categorizes data generating processes for the short sample sizes that we study.

In addition to using the corrected AIC, we also use the signs and significance of the parameters to select models. Specifically, for models that use lagged NDVI anomalies, only those estimations for which $\beta_{\mathrm{NDVI}}<0$ and $t_{\mathrm{NDVI}}<-1.7$ (i.e., $5 \%$ level of significance for a one sided test) are selected as candidate models. Similarly, for models that use lagged world prices, only those estimations for which $\beta_{\text {wprice }}>0$ and $t_{\text {wprice }}>1.7$ (i.e., $5 \%$ level of significance for a one sided test) are selected as candidates. Consequently, the selected models are consistent with economic theory and commonsense and not merely the result of a data-mining exercise.

\section{Estimation results using synthetic data}

In this section we test our methodology against a simple dynamic OLS benchmark to demonstrate the value of a state space methodology. We generate 100 realizations of 60 observation time series for each data generating process described in Section 1.1. Where relevant, we assign the following values for the parameters: $\alpha_{1}=1.2, \alpha_{2}=1, \sigma_{\varepsilon}^{2}=1, \sigma_{\zeta}^{2}=1, \beta_{1}=0.5, \beta_{2}=-0.5, \beta_{\mathrm{NDVI}}=-0.1$, $\beta_{\text {WPrice }}=0.1$, with an initial value of the $\log$ price of 1 . We use changes in the World Bank's monthly cereal price index and average NDVI anomaly changes from the sample as the exogenous drivers/values taken by the explanatory variables. For each data generating process (i.e., Models I-IV) we estimate parameters using the four models (one each for each of the four data generating process). We then report two sets of results. First, we compare bias and efficiency for each state space and dynamic OLS specification for each data generating process. Second, we study our model selection methodology using the synthetic data set described above.

Table S1 and Figs. S1-S4 in the Supplementary material summarize results of the state space methodology used in the paper and compare them with results from a more standard dynamic Ordinary Least Squares (OLS) regression. The latter is a standard (time series) regression that includes a lagged dependent variable as one of the covariates. Taken together, the results suggest that for all four data generating processes the estimates of the parameters of interest are both less biased and more efficient using the state space methodology. Further even if the estimation specification is mis-specified (for example when an M2 model estimation is used for a true M1 process), the mean errors are closer to zero using the state space methodology. For all models, the root mean square divergence of the estimated coefficient from the true parameter is between three and four times as large using a least squares regression instead of the state space method employed in the paper. For example, when the true process is Model IV and the estimation is consistent with a model IV process, then the mean error for the lagged NDVI anomaly coecient is $2.9 \%$ using the state space methodology and $-14.5 \%$ using the dynamic OLS estimation. The RMSPE using the state space method is $28.5 \%$ and the RMSPE using the dynamic OLS is $88.5 \%$. Similarly, when the true process is Model IV and the estimation is consistent with a model IV process, then the mean error for the lagged international price coecient is $1.8 \%$ using the state space methodology and $-6.8 \%$ using the dynamic OLS estimation. The RMSPE for the estimated lagged international price parameter using the state space method is $26.5 \%$ and the RMSPE using the dynamic OLS is $72.5 \%$. Figs. S1 and S2 are box plots that provide a visual confirmation of these results. Using the methodology employed in the paper, both the distribution of the estimated lagged NDVI coecient as well as the distribution of the lagged international price coefficient are less dispersed using the state space methodology. Figs. S3 and S4 show the distribution of the $t$-statistics. Less than $5 \%$ of the $t$ - 
statistics are above -1.7 (below 1.7) for the NDVI (International price) coefficients. These results underscore the importance of using an iterative estimation procedure when estimating parameters from relatively small samples of a noisy data generating process. Other iterative methods that estimate parameters of dynamic linear systems may also work well. We used the Kalman filter technique because it is both flexible and well studied (e.g., Harvey, 1990; Durbin and Koopman, 2012; Shumway and Stoffer, 2010).

\subsection{False-positive and false-negative error rates}

Tables $1 \mathrm{a}, 1 \mathrm{~b}$ and $1 \mathrm{c}$ summarize the results of the model selection process using the synthetic data. As may be expected, average AICs are lower when the model specification is consistent with the true data generating process. Table $1 \mathrm{~b}$ shows that the model selection method is robust to mis-specification. Both the false positive and false-negative error rates are low. Just $7 \%$ of the series are categorized as being influenced by weather disturbances when if fact the data generating process is consistent with no influence. Further, $7 \%$ of the series are generated by a process that has a weather influence for those series for which the methodology estimates no influence.

Further, as Table 1c shows, when the model is correctly specified, the state space methodology employed in the paper successfully categorizes weather influence $95 \%$ of the time. In contrast, the dynamic OLS methodology is successful less than $50 \%$ of the time. Taken together, these results suggest that the model selection process used in the paper is reasonably robust to misspecification. Further it significantly out-performs dynamic OLS estimation when the model is correctly specified.

\section{Results}

The results show that for most of the developing world, there are a much larger fraction of local food markets that are influenced by local weather disturbances than by the prices at which agricultural commodities are traded on international markets (Fig. 1). During 2008-2012, 19\% of the 554 commodity-location pairs in the model were affected by local weather disturbances, $9 \%$ by international prices and $4 \%$ by both weather and international prices. The model was able to identify an exogenous driver for 177 of the 554 market-commodity pairs examined (See Table S2 for detailed estimation results for weather that include the goodness of fit, the relevant parameters and $t$-statistics). For maize, $29 \%$ of the 160 market locations were affected by domestic weather disturbances (exclusively or in combination with international prices), while $13 \%$ were affected by international prices (exclusively or in combination with weather disturbances). In contrast, rice prices are affected by domestic weather in $15 \%$ of the 114 locations where prices were available, with $17 \%$ being affected by international prices (Table 2). The markets affected by local
Table 1b

Error rates in identifying weather and international drivers.

\begin{tabular}{lll}
\hline True model & \% False positive & \% False negative \\
\hline M2/M4: weather influence & 0.07 & 0.07 \\
M3/M4: world price influence & 0.13 & 0.11 \\
\hline
\end{tabular}

Table 1c

Estimates with model IV estimation and model IV process.

\begin{tabular}{lccc}
\hline & Coefficient & $t$-Stat & \% Influenced \\
\hline State space & & & \\
World price & 0.98 & 3.955 & $95 \%$ \\
NDVI & -0.10 & -3.678 & $95 \%$ \\
& & & \\
Dynamic OLS & & & $48 \%$ \\
World price & 0.093 & 1.848 & $33 \%$ \\
NDVI & -0.087 & -1.275 & \\
\hline
\end{tabular}

Notes: The table provides mean estimates of coefficients and $t$-statistics for estimation IV assuming the data generating process is also model IV. The last column measures the average number of time series for which the weather or price influence is correctly classified.

weather disturbances are nearly all in regions that grow rice locally.

The categorization of food price dynamics and the estimation of the influence of weather and international prices are robust for the following three reasons. First, both explanatory variables of interest enter with a one-month lag. Second, weather disturbances are exogenous and world prices are exogenous for most countries we study. For the overwhelming majority of countries studied, with the exception of Argentina, South Africa, Pakistan and Mexico, countries export and import only a small fraction of world trade. Third, the corrected Akaike Information Criterion (AICc) provides an additional penalty for additional explanatory variables used. For a fifth of our sample, the lagged weather disturbance provides a better fit (i.e., lower AICC) than a seasonal random walk benchmark.

Fig. 2 describes the relationship between a few select local food prices and local NDVI anomalies and. Note these figures do not come from statistical estimations, but rather represent the price data without adjustments. Even without controlling for harvest cycles and other influences it is clear that there is a relationship between domestic weather disturbances and local food prices. Eldoret, Kenya is in the middle of the fertile Rift valley, a major maize-producing region in East Africa. Favorable rainfall (a positive NDVI anomaly) in 2010 engendered a large fall in maize prices. After controlling for other factors, an NDVI anomaly of $10 \%$ is associated with a $9 \%$ decrease in price of maize in Eldoret. This decline was compounded by typical seasonal declines associated with the harvest cycle. In 2011 and 2012, adverse weather resulted in large increases in local maize prices.

Table 1a

Model selection performance using a synthetic data set. Goodness of fit and model selection using the synthetic data ( $n=100$ ).

\begin{tabular}{|c|c|c|c|c|c|c|c|c|c|c|c|}
\hline \multicolumn{6}{|c|}{ Average corrected AIC } & \multicolumn{6}{|c|}{ Model selection (\%) } \\
\hline & \multicolumn{5}{|c|}{ True data generating process } & & \multicolumn{5}{|c|}{ True model } \\
\hline & & M1 & M2 & M3 & M4 & & & M1 & M2 & M3 & M4 \\
\hline \multirow[t]{4}{*}{ Estimation model } & M1 & 219.2 & 231.4 & 233.0 & 244.7 & \multirow[t]{4}{*}{ Selected model } & M1 & 0.8 & 0.04 & 0.08 & 0.01 \\
\hline & M2 & 221.5 & 221.5 & 234.8 & 234.8 & & M2 & 0.07 & 0.83 & 0.0 & 0.02 \\
\hline & M3 & 221.4 & 233.0 & 221.4 & 233.0 & & M3 & 0.13 & 0.0 & 0.79 & 0.02 \\
\hline & M4 & 223.1 & 223.1 & 223.1 & 223.1 & & M4 & 0.0 & 0.13 & 0.13 & 0.95 \\
\hline
\end{tabular}

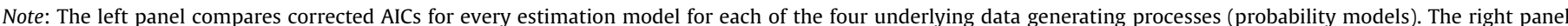
provides evidence on model selection using the synthetic data. 


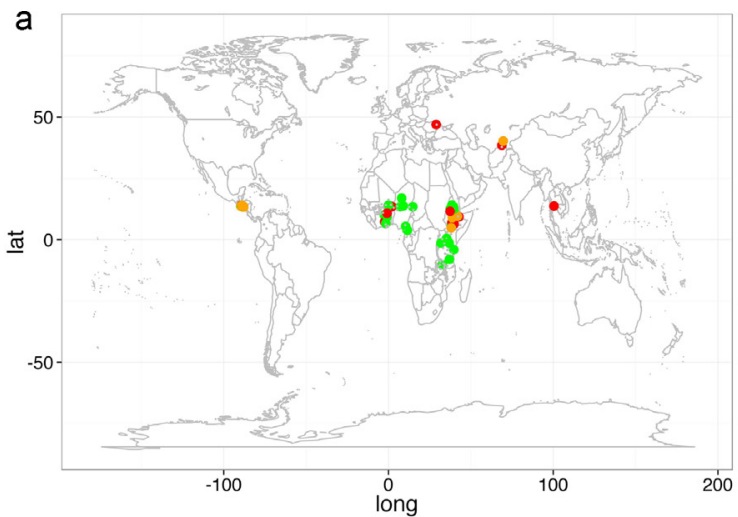

Maize Drivers Weather International Price Neither Both

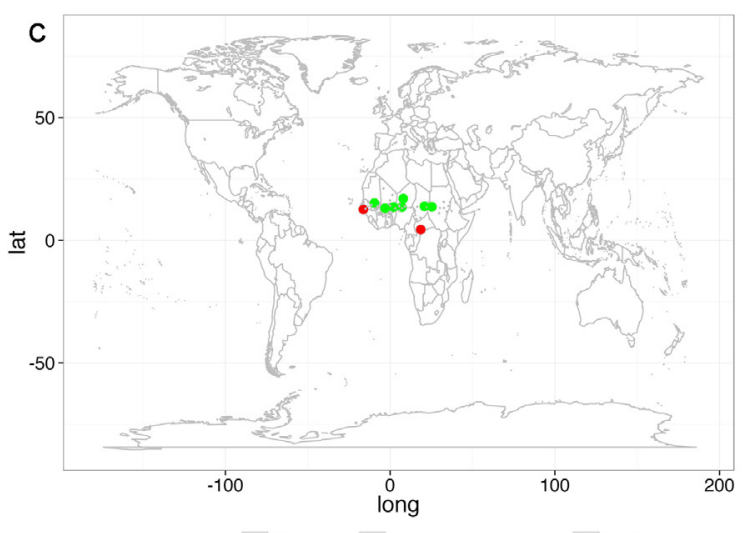

Millet Drivers Weather International Price Neither

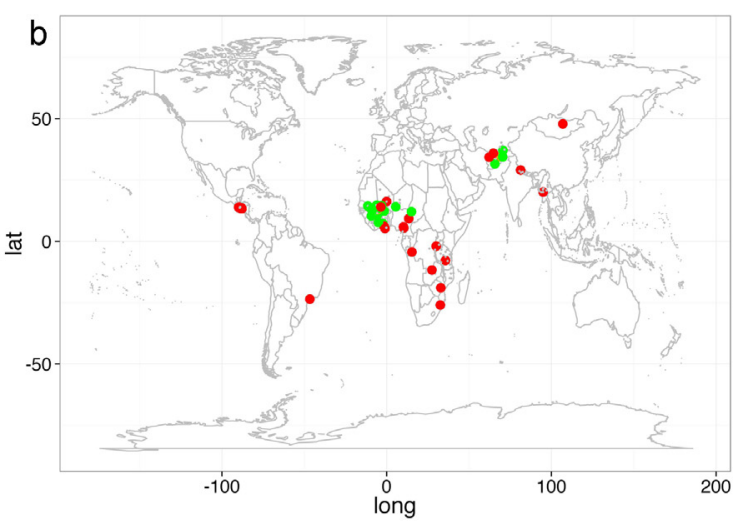

Rice Drivers Weather International Price Neither Both

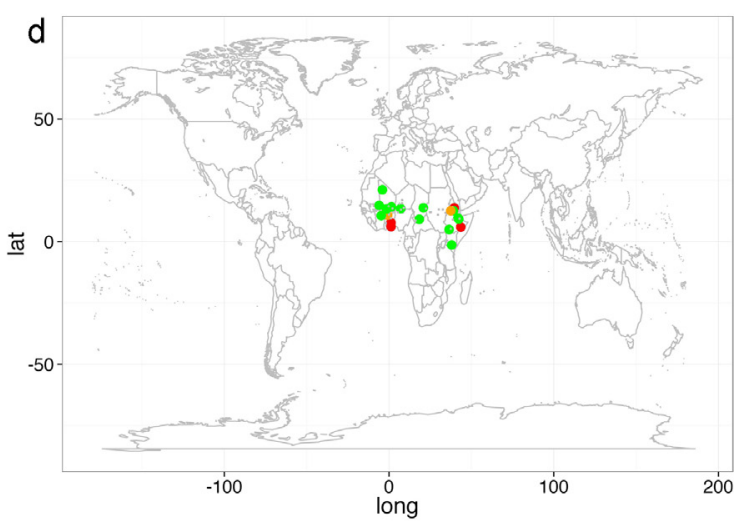

Sorghum Drivers Weather International Price Neither Both

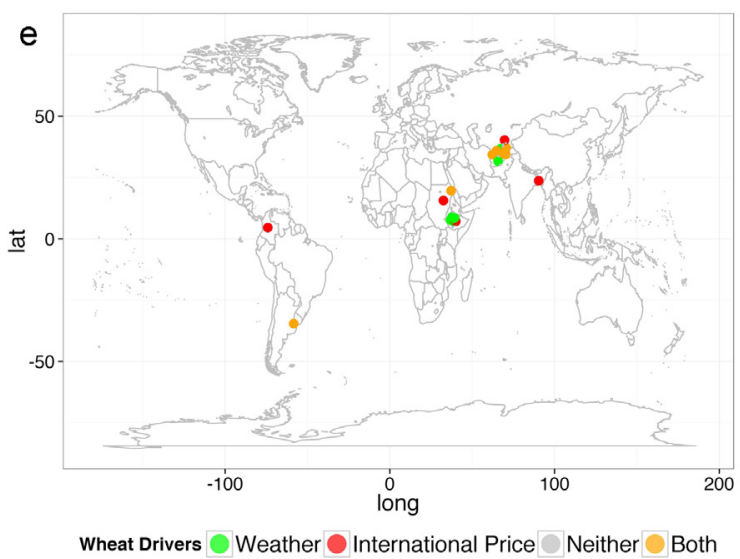

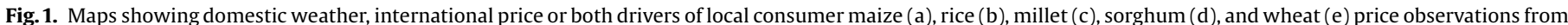

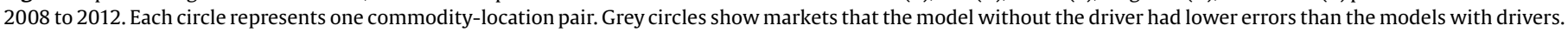

Table 2

Summary of results by commodity and influence.

\begin{tabular}{llllll}
\hline & \multicolumn{2}{l}{ Driver of local food prices } & & \\
\cline { 2 - 5 } & Weather & International & Both & Neither & Total \\
\hline Maize & 36 & 10 & 11 & 103 & 160 \\
Wheat & 13 & 8 & 8 & 39 & 68 \\
Rice & 17 & 19 & 1 & 77 & 114 \\
Millet & 13 & 1 & 0 & 53 & 67 \\
Sorghum & 17 & 2 & 1 & 48 & 68 \\
Other & 12 & 8 & 0 & 57 & 77 \\
Total & 108 & 48 & 21 & 377 & 554 \\
\hline
\end{tabular}

We found that NDVI anomalies exert a significant influence on millet prices in Kaolack. The large price increases in 2011 and 2012 were preceded by large negative NDVI anomalies. An NDVI anomaly of $10 \%$ is associated with a $6 \%$ decrease in price for millet in Kaolack, after controlling for other factors (Table 2). Afghanistan suffered from severe adverse weather for the 2011/12 season. While the coefficient for the lagged NDVI anomaly for Rice in Kabul, Afghanistan is not particularly high $(-0.4)$, the large magnitude of the shock ( $-30 \%)$ engendered a $12 \%$ increase in local rice prices, which was further compounded by typical seasonal increases (Table 2). Fig. 2 shows that Rice grown locally in West 


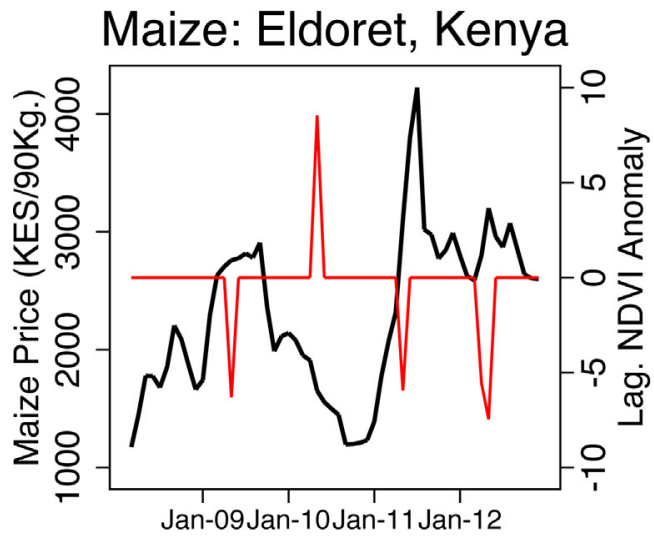

- Price - Lag. NDVI Anomaly
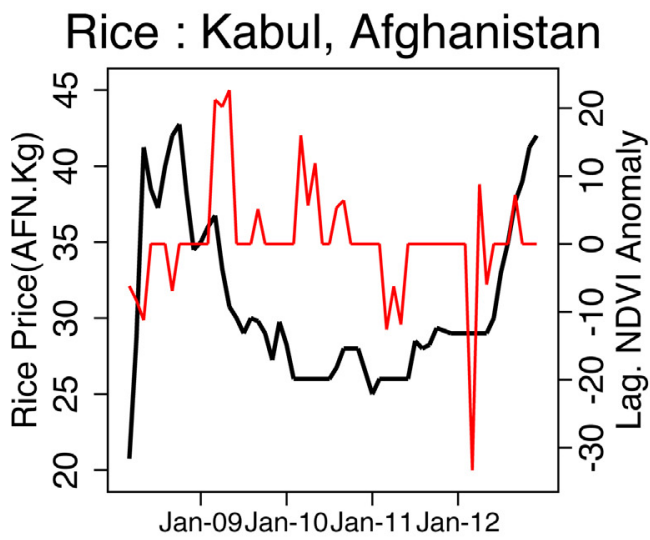

- Price - Lag. NDVI Anomaly
Millet : Kaolack, Senegal

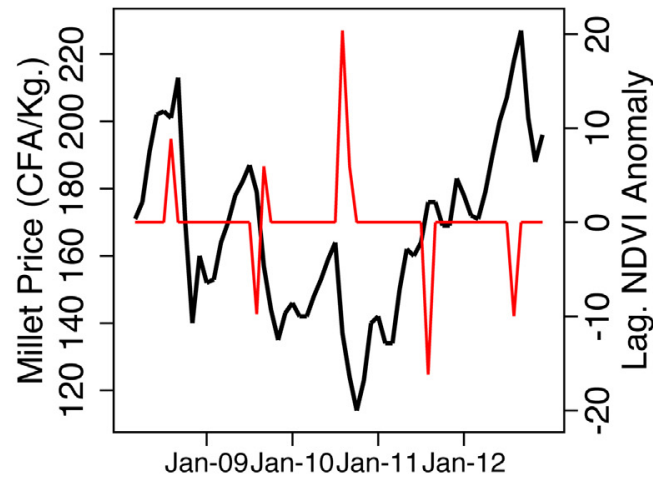

- Price - Lag. NDVI Anomaly

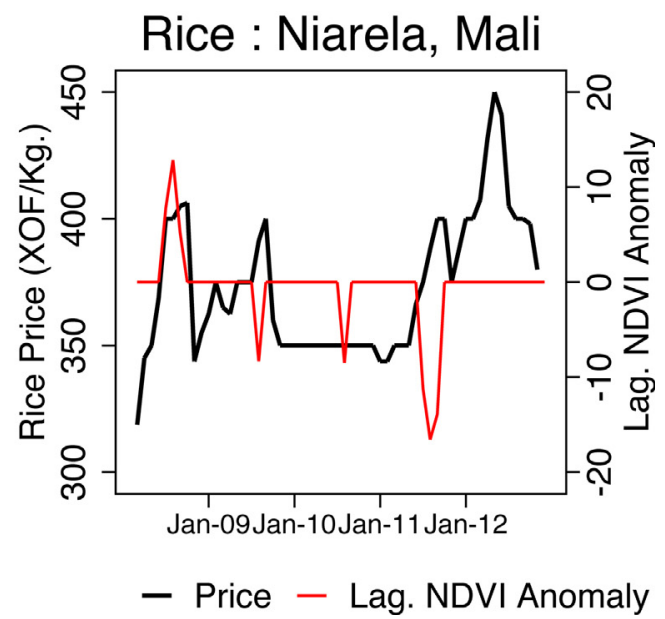

Fig. 2. Local consumer prices and NDVI anomaly time series for maize in Kenya, for millet in Senegal, rice in Mali and wheat in Afghanistan.

Africa (Niarela, Mali) is also influenced by domestic weather disturbances.

\section{Discussion}

To the best of our knowledge, the following features of our methodology and results are novel. First, our analysis uses data on both local food prices as well as information from remote sensing of vegetation to estimate parameters of a price dynamical system (see Eqs. (4)-(6)). As the simulations in section 1.3 of the supplementary information shows, this method is both parsimonious yet flexible enough to capture complex local food price dynamics for the sample sizes we study. In the supplementary section (Figs. S1-S4 and Tables S1 and 1) we show that our methodology outperforms a dynamic ordinary least squares regression. Second, we estimate weather impacts using real data (as opposed to simulations) for 51 countries in multiple regions in the developing world. Third, the analysis explicitly quantifies both a key domestic driver (i.e., domestic weather disturbances) and a key external driver (international prices) and categorizes local food markets across a large sample of locations and countries on these two dimensions.

We do not identify a major driver for 377 of the 544 markets. There are three possible reasons for this result. First, we are only capturing short run impacts. In the short run prices may not respond. Further analysis is needed to develop methods that can tease out long-run impacts while still remaining parsimonious. Second, government interventions could mitigate, perhaps only in the short run, the impacts of the two drivers we study. Third, markets may be oligopolistic with, for example, a few market intermediaries, and as a consequence prices may not reflect demand and supply shocks. Yet, it is worth noting that our framework is able to explain local food price movements for a third (32\%) of the markets we study, especially given the fact that available food price time series are typically short and noisy and that many of the markets studied are in isolated, data-sparse areas of the world.

Tschirley and Jayne (2010) have convincingly argued that discretionary government policies also play an important role in influencing local food price dynamics. While our findings are able to quantify the influence of a major driver of local food price dynamics (i.e., weather disturbances), we are unable to measure, and therefore account for, the influence of agricultural policies for a wide range of countries. In future work, the influence of policies may also be studied along with the important drivers of local food prices whose influence we are able to identify and measure in this study. Further, even though we cannot account for the influence of food policies, we still find a robust impact of lagged weather disturbances for $20 \%$ of the markets in our sample. It is also worth noting that, while we focus on measuring short-run impacts, our methodology is flexible enough to allow for a given anomaly to engender a price response over several periods. This is because we allow for a time-varying and stochastic trend. Consequently, the 
indirect influence of a given anomaly may, in fact, take several months to dissipate.

In addition to our inability to measure the influence of policies, there are, at least, two other major limitations to our study. First, as mentioned above, we focus on estimating the short run impacts of world prices and weather shocks. In fact, world prices may exert an impact in the longer run. A more elaborate empirical framework may first measure the impact of world prices on major regional hubs and then examine whether shocks get transmitted from these regional hubs to other markets. Second, and related, our model does not measure the impact of weather shocks in the context of food market integration within countries. In part, this is because the markets for which we have data are not representative at the national level. While there exists a large literature on food market integration in developing countries, for example, the references in Minot (2011), taken together, the majority of this literature does not quantify other factors that may influence local food markets. Baffes et al. (2015) constitutes one exception but differs from this study in that it focuses exclusively on one country. Future work may build on our framework to develop a more comprehensive understanding of local food price movements across a large number of countries in the developing world.

An improved understanding of the influence of weather disturbances and international price shocks on rural economies will inform public policies that are designed to mitigate the adverse impacts of weather disturbances on the poorest communities in the developing world. Food price time series data can be usefully combined with remote sensing data to provide more accurate quantitative assessments of the economic interventions on rural livelihoods and poverty. In particular, understanding and adjusting for the role of weather disturbances remains a challenge to any quantitative analysis of rural livelihoods. Continuous monitoring of these relationships will allow us to understand where domestic disturbances are affecting local food availability.

\section{Author contributions}

MEB and VK designed the methodology and wrote the paper, MEB obtained the data and VK conducted modeling.

\section{Acknowledgement}

This work was funded under a grant from the US Agency for International Development Famine Early Warning Systems Network project.

\section{Appendix A. Supplementary data}

Supplementary data associated with this article can be found, in the online version, at http://dx.doi.org/10.1016/j. gloenvcha.2015.08.003.

\section{References}

Baffes, J., Dennis, A., 2013. Long-Term Drivers of Food Prices. World Bank, Washington, D.C p. 37.

Baffes, J., Kshirsagar, V., Mitchell, D., 2015. What Drives Local Food Prices? Evidence from the Tanzanian Maize Market. World Bank Policy Research Working Paper 7338. The World Bank, Washington, D.C.

Barrett, C., 2008a. Spatial Market Integration, second ed. New Palgrave Dictionary of Economics.

Barrett, C.B., 2008b. Smallholder market participation: concepts and evidence from eastern and southern Africa. Food Policy 33, 299-317.

Becker-Reshef, I., Justice, C. Sullivan, M., Vermote, E., Tucker, C.J. Anyamba, A. Small, J., Pak, E., Masuoka, E., Schmaltz, J., Hansen, M., Pittman, K., Birkett, C., Williams, D., Reynolds, C., Doorn, B., 2010. Monitoring global croplands with coarse resolution earth observations: the global agriculture monitoring (GLAM) project. Remote Sens. J. 2, 1589-1609.
Bradbear, C., Friel, S., 2013. Integrating climate change, food prices and population health. Food Policy 43, 56-66.

Brockwell, P.J., Davis, R.A., 2009. Time Series: Theory and Methods. Springer.

Brown, M.E., 2014. Food Security, Food Prices and Climate Variability. Earthscan Routledge Press, London.

Byerlee, D., Jayne, T.S., Myers, R.J., 2006. Managing food price risks and instability in a liberalizing market environment: overview and policy options. Food Policy 31, 275-287.

Cook, A., 1999. Market Integration Analysis for FEWS. FEWS ARD/USAID p. 11.

Deaton, A., Laroque, G., 1992. On the behavior of commodity prices. Rev. Econ. Stud. $59,1-23$.

Deaton, A., Laroque, G., 1996. Competitive storage and commodity price dynamics. J. Polit. Econ. 104, 896-923.

Durbin, J., Koopman, S.J., 2012. Time Series Analysis by State Space Methods. Oxford University Press, Oxford.

Fama, E.F., 1965. The behavior of stock-market prices. J. Bus. 38 (1), 34-105.

Fama, E.F., 1970. Efficient capital markets: a review of theory and empirical work. J. Finance 25, 383-417.

FAO, 2012. Food, Agriculture and Cities. The Challenges of Food and Nutrition Security, Agriculture and Ecosystem Management in an Urbanizing World United Nations Food and Agriculture Organization, Rome, Italy p. 48.

Feng, X., Amilcare, P., Rodriguez-Iturbe, I., 2013. Changes in rainfall seasonality in the tropics. Nat. Clim. Change 3, 811-815.

Fensholt, R., 2004. Earth observation of vegetation status in the Sahelian and Sudanian West Africa: comparison of terra MODIS and NOAA AVHRR satellite data. Int. J. Remote Sens. 25, 1641-1659.

Friedl, M.A., McIver, D.K., Hodges, J.C.F., Zhang, X.Y., Muchoney, D., Strahler, A.H., Woodcock, C.E., Gopal, S., Schneider, A., Cooper, A., Baccini, A., Gao, F., Schaaf, C., 2002. Global land cover mapping from MODIS: algorithms and early results. Remote Sens. Environ. 83, 287-302.

Funk, C.C., Budde, M.E., 2009. Phenologically-tuned MODIS NDVI-based production anomaly estimates for Zimbabwe. Remote Sens. Environ. 113 (1), 115-125.

Garg, T., Barrett, C.B., Gómez, M.I., Lentz, E.C., Violette, W.J., 2013. Market prices and food aid local and regional procurement and distribution: a multi-country analysis. World Dev. 49, 19-29.

Golden, C.D., Fernald, L.C.H., Brashares, J.S., Rasolofoniaina b, Kremen, J.R., C, 2011. Benefits of wildlife consumption to child nutrition in a biodiversity hotspot. Proc. Natl. Acad. Sci. U. S. A. 108, 19653-19656.

Gustafson, R.L., 1958. Implications of recent research on optimal storage rules. J. Farm Econ. 40, 290-300.

Handa, S., Mlay, G., 2006. Food consumption patterns, seasonality and market access in Mozambique. Dev. Southern Africa 23, 541-560.

Harvey, A.C., 1990. Forecasting, Structural Time Series Models and the Kalman filter Cambridge University Press, Cambridge, UK.

Hazell, P.B., 2013. Options for African agriculture in an era of high food and energy prices. Agric. Econ. 44 (s1), 19-27. doi:http://dx.doi.org/10.1111/agec.12047.

Headey, D., Fan, S., 2008. Anatomy of a crisis: the causes and consequences of surging food prices. Agric. Econ. 39, 375-391.

Headey, D.D., 2013. The impact of the global food crisis on self-assessed food security. World Bank Econ. Rev. 27 (1), 1-27.

Hoefsloot, P., Ines, A., Dam, J.V., Duveiller, G., Kayitakire, F., Hansen, J., 2012. Combining Crop Models and Remote Sensing for Yield Prediction: Concepts, Applications and Challenges for Heterogeneous Smallholder Environments. Report of Joint CCFAS/JRC Workshop, Ispra, Italy p. 48.

Hurvich, C.M., Tsai, C.-L., 1989. Regression and time series model selection in small samples. Biometrika 76, 297-307.

Ihle, R., Cramon-Taubadel, S.V., Zorya, S., 2011. Measuring the Integration of Staple Food Markets in Sub-Saharan Africa: Heterogeneous Infrastructure and Cross Border Trade in the East African Community. CESIFO WORKING PAPER NO. 3413, Gottingen.

Justice, C.O., Vermote, E., Townshend, J.R.G., Defries, R., Roy, D.P., Hall, D.K., Salomonson, V.V., Privette, J.L., Riggs, G., Strahler, A., Lucht, W., Myneni, R.B., Knyazikhin, Y., Running, S.W., Nemani, R.R., Wan, Z.M., Huete, A.R., van Leeuwen, W., Wolfe, R.E., Giglio, L., Muller, J.P., Lewis, P., Barnsley, M.J., 1998. The moderate resolution imaging spectroradiometer (MODIS): land remote sensing for global change research. IEEE Trans. Geosci. Remote Sens. 36, 1228-1249.

Karnieli, A., Agam, N., Pinker, R.T., Anderson, M.C., Imhoff, M.L., Gutman, G.G., Panov, N., Goldberg, A., 2010. Use of NDVI and land surface temperature for assessing vegetation health: merits and limitations. J. Clim. 23, 618-633.

Lo, A.W., MacKinlay, A.C., 2011. A Non-random Walk Down Wall Street. Princeton University Press, Princeton, NJ.

Malkiel, B.G., 1973. A Random Walk Down Wall Street. WW Norton \& Company, New York City.

Meinhold, R.J., Singpurwalla, N.D., 1983. Understanding the Kalman filter. Am. Stat. $37,123-127$

Minot, N., 2011. Transmission of World Food Price Changes to Markets in SubSaharan Africa. IFPRI Discussion Paper 1239. International Food Policy Research Institute (IFPRI), Washington, D.C p. 34.

Newbery, D.M., Stiglitz, J.E., 1981. The Theory of Commodity Price Stabilization: A Study in the Economics of Risk. Clarendon Press, Oxford.

Pettorelli, N., Vik, J.O., Mysterud, A., Gaillard, J.-M., Tucker, C.J., Stenseth, N.C., 2005. Using the satellite-derived NDVI to assess ecological responses to environmental change. Trends Ecol. Evol. 20, 503-510.

Pfeifer, M., Lefebvre, V., Gonsamo, A., Pellikka, P.K.E., Marchant, R., Denu, D., Platts, P. J., 2014. Validating and linking the GIMMS leaf area index (LAI3g) with environmental controls in tropical Africa. Remote Sens. J. 6, 1973-1990. 
Rasmussen, M.S., 1992. Assessment of millet yields and production in northern Burkina Faso using integrated NDVI from the AVHRR. Int. J. Remote Sens. 13, 3431-3442.

Sahn, D.E., 1989. Seasonal Variability in Third World Agriculture. Johns Hopkins Press, Baltimore, MD.

Samuelson, P.A., 1965. Proof that properly anticipated prices fluctuate randomly. Ind. Manag. Rev. 6, 41-49.

Shumway, R.H., Stoffer, D.S., 2010. Time Series Analysis and its Applications. Springer, Heidelberg New York.

Swinnen, J., Squicciarini, P., 2012. Mixed messages on prices and food security. Science 335, 405-406.

Trostle, R., Marti, D., Rosen, S., Westcott, P., 2011. Why Have Food Commodity Prices Risen Again? US Department of Agriculture Economic Research Service (ERS), Washington DC p. 29.

Tschirley, D., Jayne, T.S., 2010. Exploring the logic behind Southern Africa's food crises. World Dev. 38, 76-87.

Tucker, C.J., 1979. Red and photographic infrared linear combinations for monitoring vegetation. Remote Sens. Environ. 8, 127-150. ul Haq, Z., Nazli, H., Meilke, K., 2008. Implicaitons of high prices for poverty in Pakistan. Agric. Econ. 39, 477-484.

Von Braun, J., 2008. Rising Food Prices: What Should Be Done? IFPRI Policy Brief International Food Policy Research Institute, Washington, D.C.

Vrieling, A., de Beurs, K.M., Brown, M.E., 2011. Variability of African farming systems from phenological analysis of NDVI time series. Clim. Change 109, 455-477.

Webb, P., 2010. Medium- to long-run implications of high food prices for global nutrition. J. Nutr. 140, 143S-147S.

World Bank, 2008. World Development Report: Agriculture for Development. The World Bank, Washington, D.C.

World Bank, 2014. Wrold Development Report: Risk and Opportunity-Managing Risk for Development. The World Bank p. 362.

Wright, B.D., Williams, J.C., 1991. Storage and Commodity Markets. Cambridge University Press, Cambridge, UK.

Zant, W., 2013. How is the liberalization of food markets progressing? market integration and transaction costs in subsistence economies. World Bank Econ. Rev. 27, 28-54. 